\title{
Development of a transport management system of a flexible production system
}

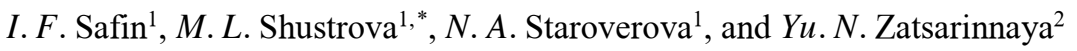 \\ ${ }^{1}$ Department of Automated systems for collecting and processing information, Kazan National \\ Research Technological University, K. Marksa str., 68, Kazan, 420015, Russia \\ ${ }^{2}$ Department of Power stations named after V.K. Shibanov, Kazan State Power Engineering \\ University, Krasnoselskaya str., 51, Kazan, 420066, Russia
}

\begin{abstract}
The intensive development of information technologies and software and hardware of control systems creates conditions for active processes of digitalization of the industry. One of the relevant areas of digitalization in production is the development and implementation of flexible production systems that expand the functionality of production lines and increase the efficiency of the production process. This paper deals with the development of a transport management system of a flexible production system. A solution is proposed that includes a block diagram of the system, hardware and functional logic.
\end{abstract}

\section{Introduction}

The transition to a digital economy implies the active introduction of digital technologies in all areas. Digital retail and banking are developing most effectively[1]. The largest players in these markets have long called themselves IT companies. Big steps in the implementation of digital systems are currently implemented in business[2], transport systems[3], science, education, medicine and even in agriculture[4]. Digital technologies in production are also actively developing. But the situation in this area is slightly different from other areas.

Practically all design and engineering activities have gone digital. Financial and economic activities and strategic management are also impossible without specialized information systems. Automated process control systems exist and have been successfully used for more than a dozen years. Nevertheless, it is not necessary yet to talk about the implementation of the concept of digital production at most enterprises.

This is primarily due to the fact that the processes of automation of activities within enterprises are very important, but they do not determine digital production. Digitalization of an enterprise means the transfer of all company processes to digital format: customer service, sales management, production cycle and technological processes, as well as processes of personnel training and modeling of technological processes in order to optimize them [5-7] - all aspects of the enterprise are gradually automated and digitized. Intelligent management systems are also being actively developed and implemented.

\footnotetext{
*Corresponding author: shu.ma@bk.ru
} 
There are 5 main tasks that need to be solved for the transition to digital form of production management: speed of bringing products to market; manufacturing flexibility; product quality; efficiency; security.

Each of the points is important in its own way, but within the framework of this research we would like to dwell on such a concept as "Production flexibility".

The modern market is characterized by continuous changes and the fact that each final product is individualized for the final consumer. As a result, manufacturers are forced to increase production flexibility. This reorientation of production entails the emergence of a large number of problems associated with transportation, storage, introduction of new products, and so on. For this reason, the development of a transport management systems and the introduction of identification systems is one of priority tasks of modern and progressive production. Furthermore, the identification system allows to solve problems related to the quality management system, which allows you to constantly improve production efficiency and the quality of products. The aim of this work is developing a transport management system of a flexible production system.

\section{Materials and methods}

Let's considered the solution to this problem on the basis of flexible production system (Figure 1), which is engaged in the manufacture of products from various materials. The production is equipped with modern $\mathrm{CNC}$ milling machines, a KUKA robot manipulator with a linear axis, a robot control system and a FPS management system based on the Siemens S7-1200 controller.

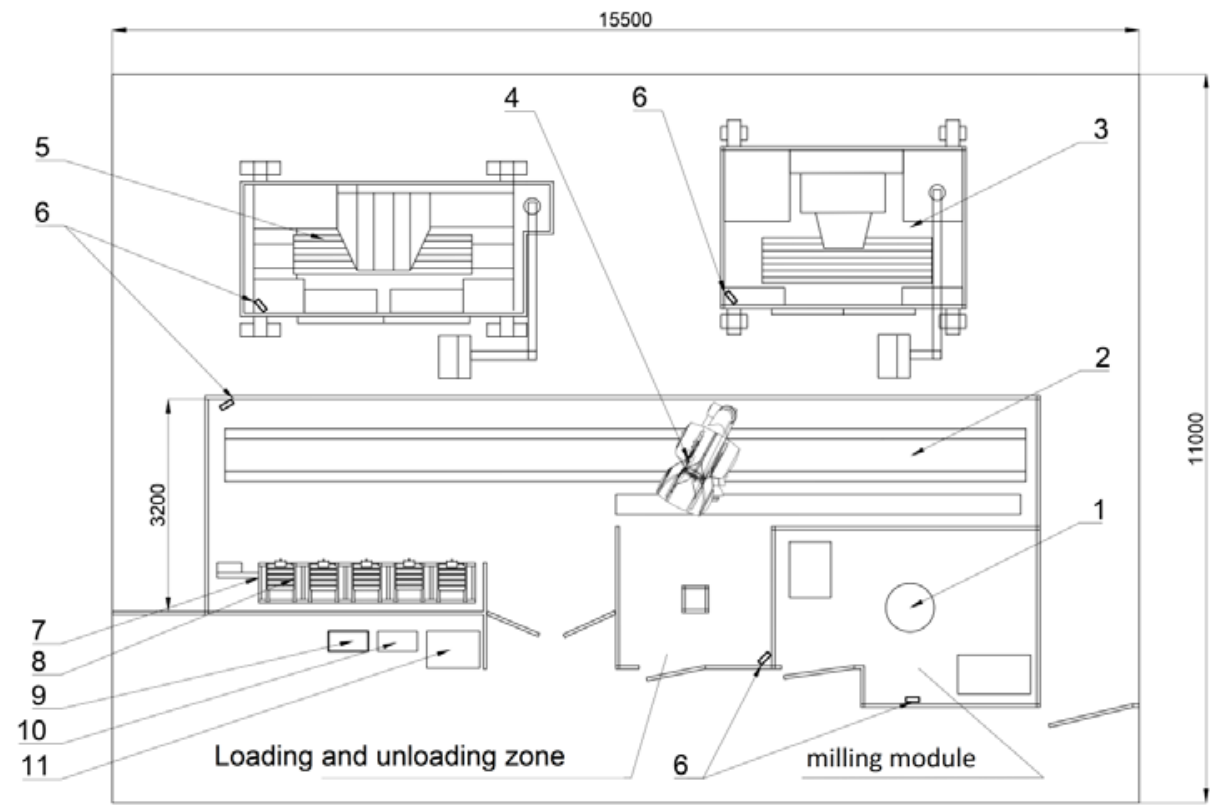

Fig. 1. FPS layout scheme:1- KUKA positioner, 2- KUKA linear unit ; 3 - HEDELIUS RS 605 machine, 4 - KUKA KR 240 R2900 robot, 5- HEDELIUS C 80 machine, 6- reader RFID 680, 7 pallet warehouse, 8 - pallet, 9 - identification and control cabinet, 10- power cabinet,.11- FPC control cabinet and KR C4 system.

The first stages of system development were the analysis of all business and technological processes of the enterprise, as well as the range of manufactured products. A 
business process model developed based on the data obtained is represented at Figure 2. It allows you to visually represent all the necessary processes in the manufacture of a product.

None of the methods analyzed was widely used in the energy sector because each method was designed by developers to solve a local problem. In this regard, for example, the advantage of the Venturi method where the wind rose has a pronounced character becomes a disadvantage in geographical areas where winds are a rare. The application of cleaning based on the occurrence of Ampere force remains relevant for cleaning snow from a module located in the steppe but such a system is not suitable for cleaning dust in the desert.

The conclusion that should be drawn from this table is that the main advantage that they strive for is the autonomy of a device.

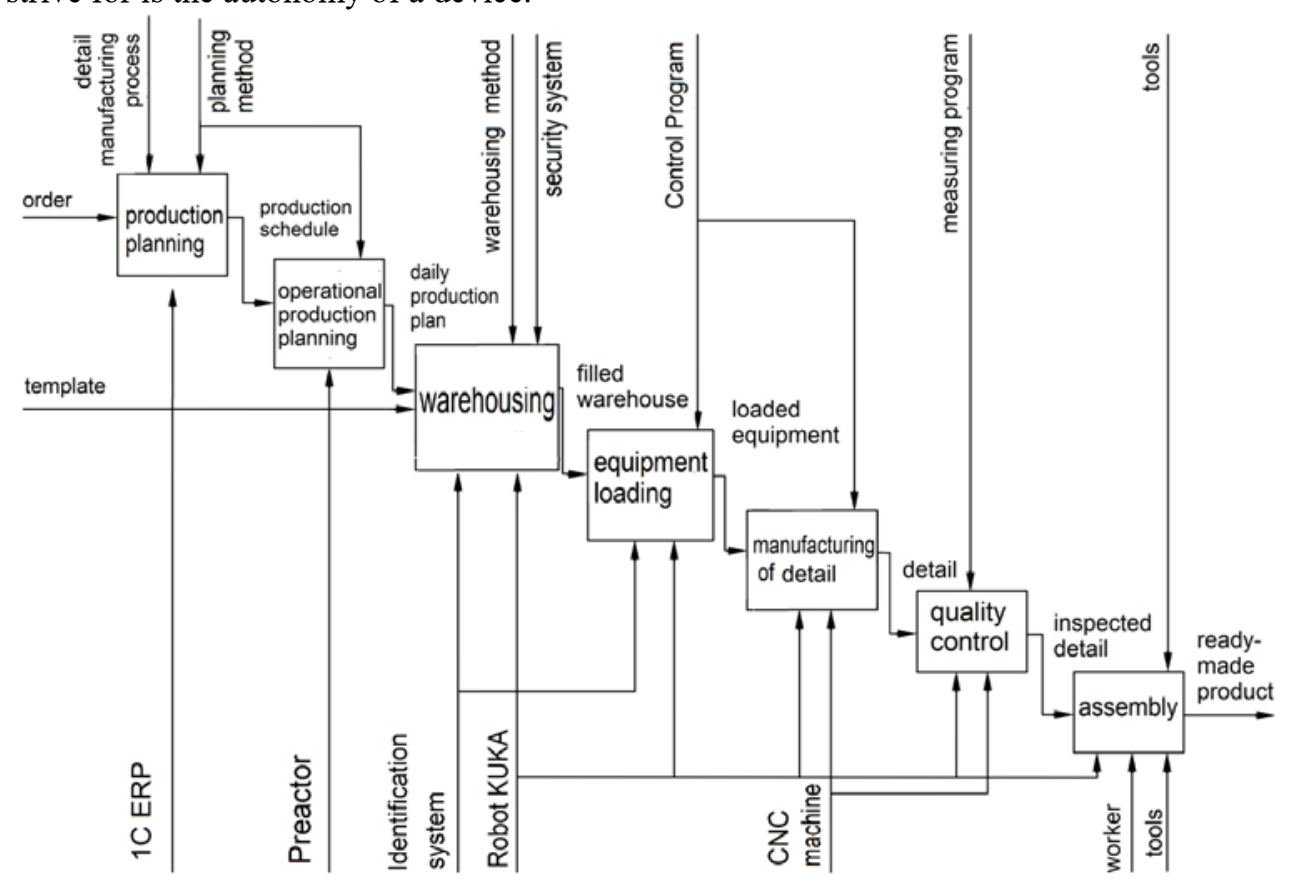

Fig. 2. FPS business process model.

A scheme of the architecture of the production enterprise management system represented at Figure 3 was developed for the correct construction of the future system.

This scheme defines the links between the levels of enterprise management, as well as the hardware and software for each level. The area in which the solution of the problem of development of a transport management system lies is included in the framework of the transportation system being developed and cover the level of production process management and the level of objects and devices.

The transport management system is divided into a transportation subsystem and an identification subsystem. The transport subsystem is based on the KUKA robot and the MXAutomation software product. This software allows you to control your robot using an industrial controller using the PROFINET protocol.

The identification subsystem was based on radio frequency identification, in particular, Siemens equipment of the SIMATIC RF600 UHF series of reading range. The transport management system is controlled by a Siemens S7-1500F controller with enhanced safety functions. 


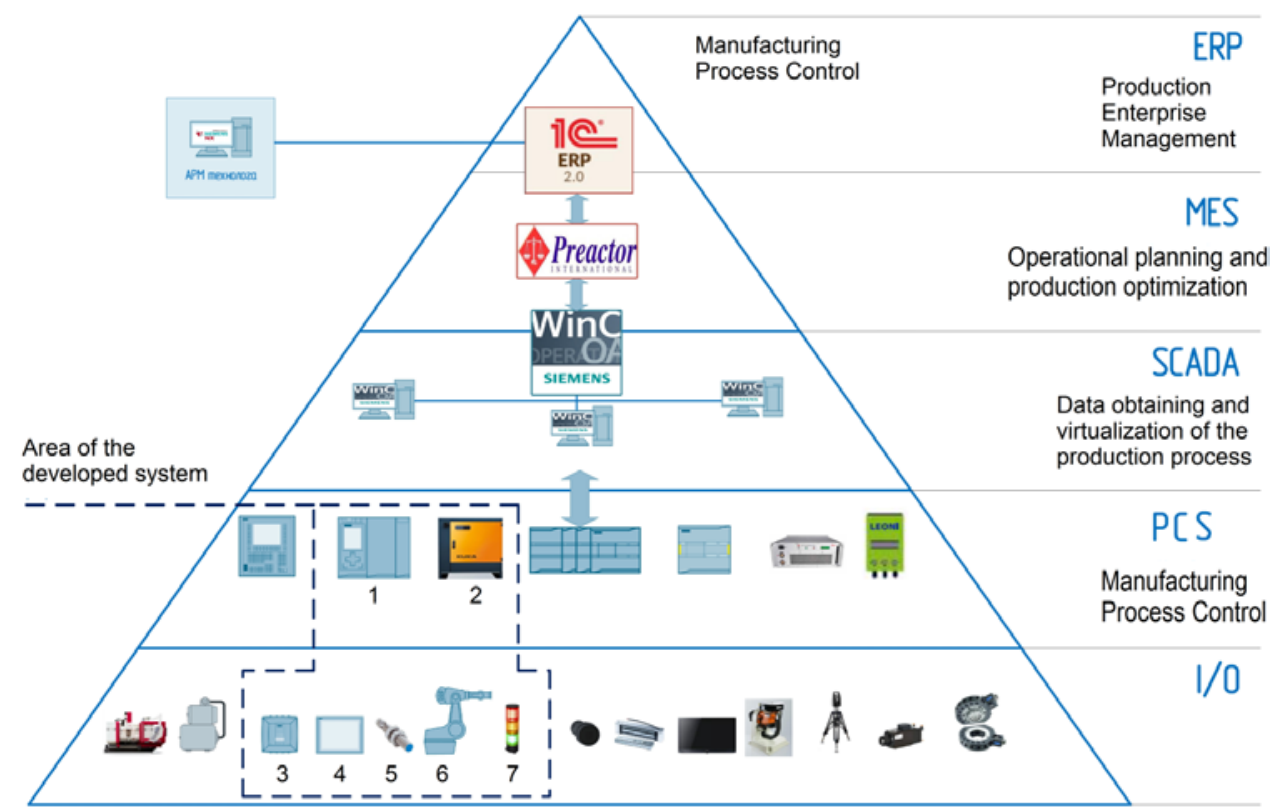

Fig. 3. Integration scheme of the production and enterprise management system: 1- Identification and robot control system controller,2-KUKA robot controller,3-RFID Reader,4- HIM panel,5-sensors,6KUKA robot,7- LED column.

An operator panel is connected to the controller to visualize the states of the transport system, and an identification system (main and backup). To improve the reliability of the identification system, it was decided to use a readout diagnostic system. At the points where pallets are identified with a tag, inductive sensors are additionally installed, which determine the presence of pallets. To eliminate accidents that occur when the tags are not read, a backup identification system based on a mobile RFID reader is provided. All communications between equipment are carried out using the PROFINET protocol.

For the correct placement of the identification system in the FPS loop, a special experiment with RFID equipment was carried out. During of the experiment, the situations of reading the tags at the identification points were emitted. For each point, the tags were placed in the positions in which the robot would install them together with the pallet (Figure 4). And by moving the antenna, positions were found where the received signal power was the most stable and highest.

The identification system allows solving problems not only related to the traceability of products during transportation in real time, but also allows the creation of electronic product passports. For the development of such passports, a special codifier was developed (Figure 5). 


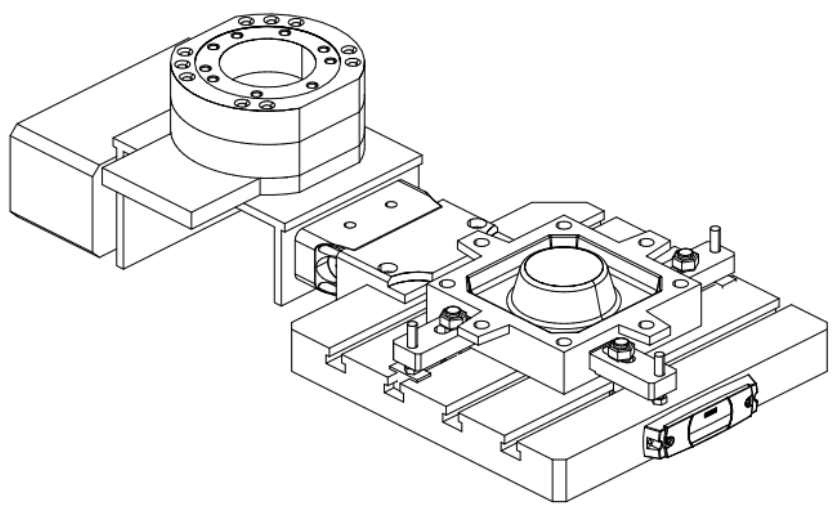

Fig. 4. Scheme of fixing the tag on the pallet and robot's gripping for pallets.

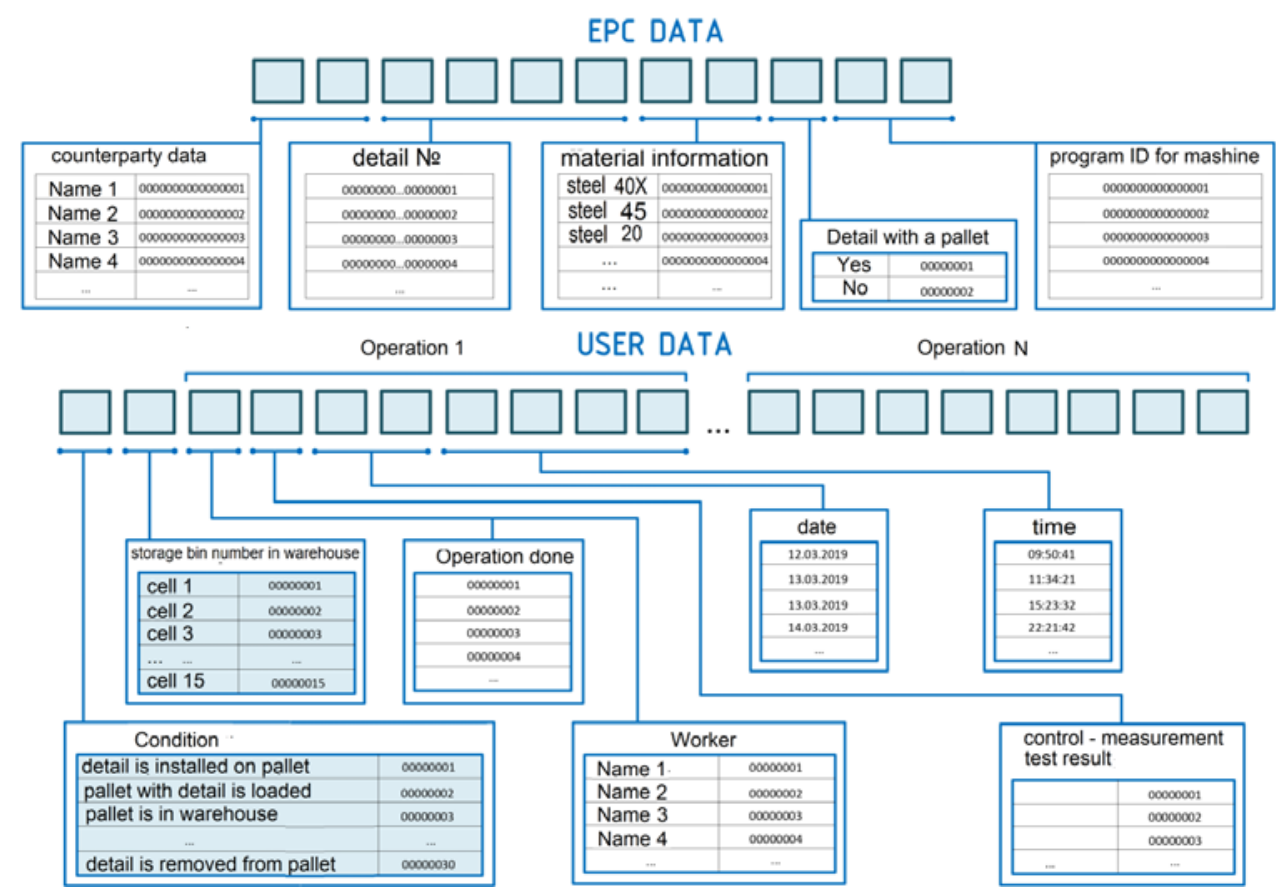

Fig. 5. Information codifier for tags.

The codifier is divided into two parts, where in the first part information about the part, material and ID number of the program for the machine is written; and in the second part information about the state, the number of the storage cell and blocks with information about the operations performed, which contains information about the operation performed, worker, result of control and measuring test, date and time. After the product is manufactured, the tag will store all information about the work done and the results, with the help of which the consumer can find out the entire course of the production process.

As part of solving transportation problems, a transportation algorithm (Figure 6) and a storage functioning algorithm (Figure7) were developed. 
Fig. 6. Algorithm for moving the robot
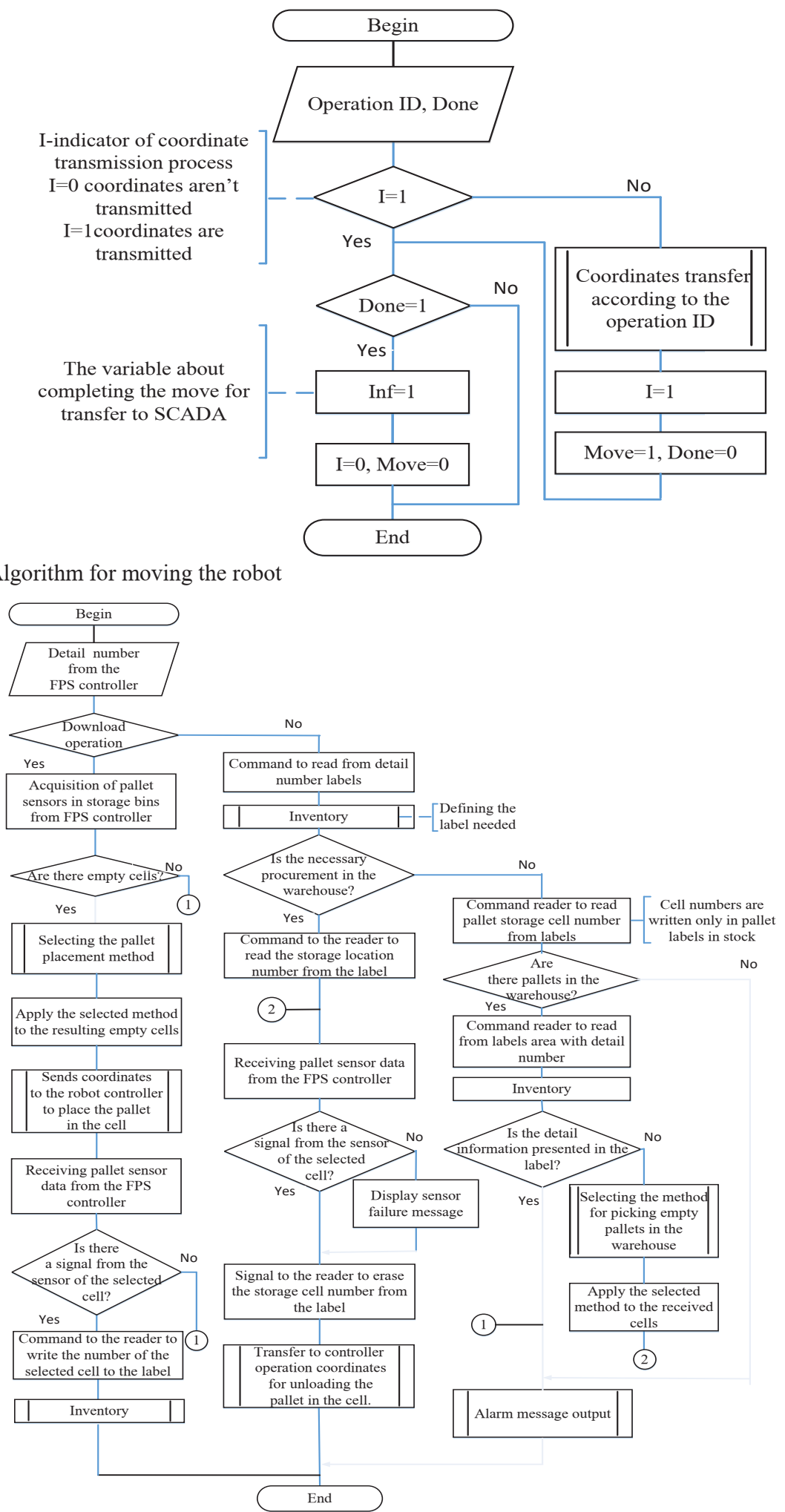

Fig. 7. Storage functioning algorithm 


\section{Results}

The main result of this research is the development of the concept, hardware environment and logic of the work of the transport management system of the flexible production system. The main feature of this storage is that it will be dynamic, i.e. pallets will not be strictly attached to certain cells. To place or remove pallets, an identification system and special methods are used, which are described in the work.

A radio frequency identification system allows registration of pallets with products in real time as part of the digitalization of production, and also contributes to an increase in the efficiency of the accounting and transportation of parts.

The advantages of implementing this management system are:

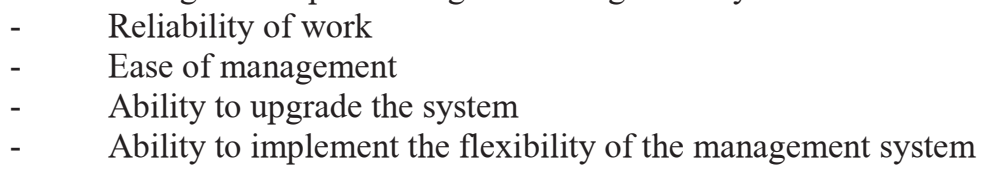

\section{Conclusion}

The active development of information technologies, software and equipment inevitably leads to qualitative changes in the production process, as well as the modernization of automation systems. An important aspect of modern digitalization of production is the transition to flexible production systems.

The system developed in this work solves the problems associated with the transportation of products within the loop of a flexible production system. The application of the system proposed in this work allows to increase the efficiency of production and ensure its flexibility, which is a significant competitive advantage in modern conditions.

\section{References}

1. Akhmetshin E.M., Meshkova G.V., Vysotskaya O.A., Alekhina N.A., Surikov Yu.N., Shichiyakh R.A. DIGITALIZATION: CURRENT STATUS AND PROSPECTS FOR FURTHER DEVELOPMENT Talent Development and Excellence. 2020. T. 12. № Suppl.3. C. 488-499.

2. Salimyanova I.G., Novikov A.A., Novikova E.V., Lushchik I.V., Savderova A.F., Berezina N.V., Rudenko L.G., Allalyev R.M. ECONOMY DIGITALIZATION: INFORMATION IMPACT ON MARKET ENTITIES Journal of Environmental Treatment Techniques. 2019. T. 7. № 4. C. 654-658.

3. Staroverova, N.A.,Shustrova, M.L., Zatsarinnaya, Y.N. The development of rolling-stock virtual simulator.Journal of Physics: Conference Series, 2019, 1399(4), 044025

4. M.Vasileva, I. Ismagilov, A. Gerasimov. , The development of modern automated image processing and transfer systems for agriculture unmanned aerial vehicles / E3S Web of Conferences. 2020, т.161, в.01087

5. Gainullina A.A., Nurgaliev R.K., Ryjov D.A. Training Software Complex "Automated Control System of Enterprise" / International Journal of Engineering and Advanced Technology . - 2019, T.9, № 1. P. 7476-7481.

6. Buitenhek R., Baynat B., Dallery Y. Production capacity of flexible manufacturing systems with fixed production ratios. International Journal of Flexible Manufacturing Systems. 2002. T. 14. № 3. C. 203-225.

7. Gaynullin, R., Zatsarinnaya, Y., Staroverova, N. Creation of the virtual exercise machine of the technological production with the use of OMEGALAND dynamic modelling environment/ IOP Conference Series: Materials Science and Engineering, 2019, 537(3), 032019 